ARID International Journal of Informetrics (AIJI) VOL: 1, NO 1, July 2020

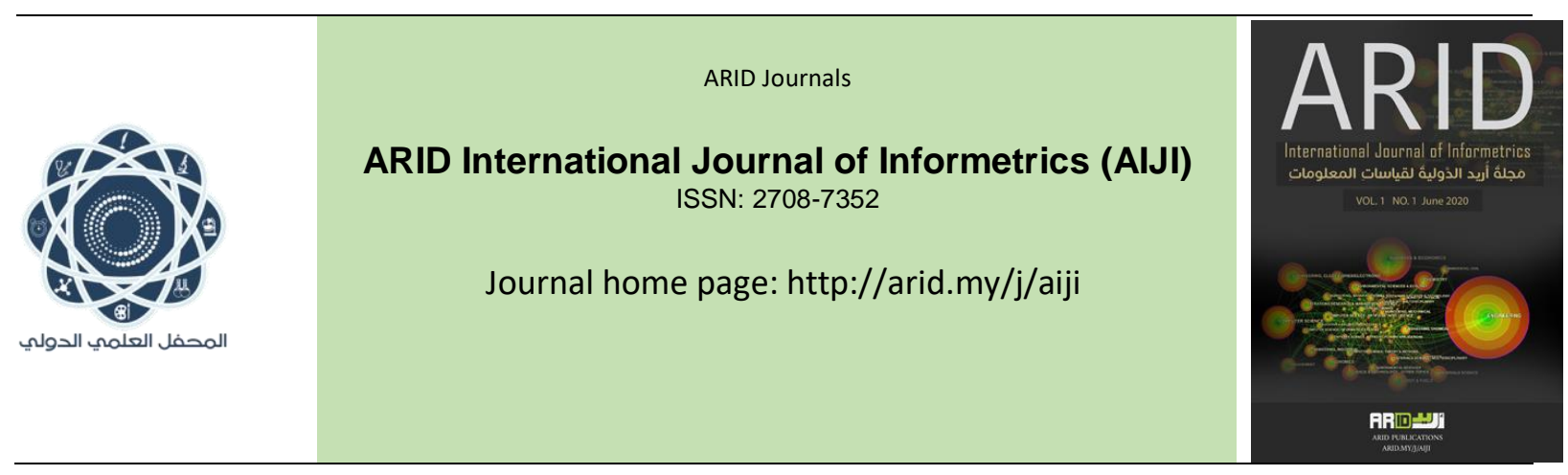

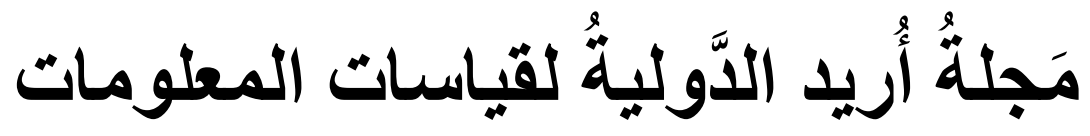 العدد 1 ، المجلد 1 ، تموز 2020 م
}

\section{ARID Platform after Four Years of Its Establishment (2016-2020): A bibliometric Study}

\author{
Maryam Qays*1 $^{*}$, Saif Yousif ${ }^{2}$, Abdelrahman Farrag ${ }^{3}$ \\ 1- Faculty of Engineering and Built Environment, UKM university, Selangor, Malaysia. \\ 2- Faculty of Dentistry, University Of Malaya, Selangor, Malaysia. \\ 3- Information Sciences Department, Beni-Suef University, Egypt

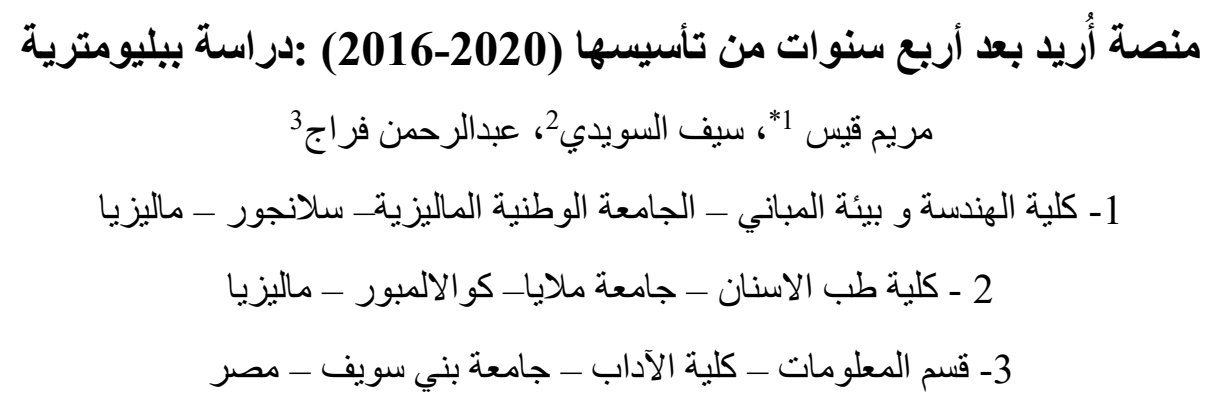

aiji@arid.my

arid.my/0001-1034

https://doi.org/10.36772/arid.aiji.2020.111 


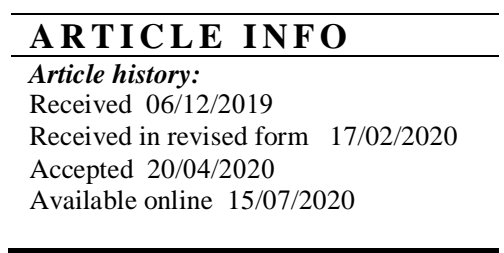

\begin{abstract}
After four years of the official opening of ARID (Arabic Researcher ID) platform, the number of its users exceeded 44 thousand who can speak Arabic from all over the world. ARID platform is the first Arabic platform to serve scientific research in a way that keeps pace with technical development, which made the access to the scientific research available to all users. The study aims to introduce ARID platform in the language of numbers to transmit a statistical picture for the scientists, experts and researchers on the first digital platform for Arabic speakers and how it can be benefit from this experience and data analysis in digital platforms that serve the Arabic language. The study concluded several results, however, the most important of which is that the number of users on ARID platform is increasing dramatically, and their numbers vary in different countries and universities. The platform included a wide range of various disciplines, most notably the specializations of educational sciences, sciences, arts, and political sciences, with a large number of holders of higher degrees (masters and doctorate), as they exceeded eight thousand users. Participation in conferences tops the list of academic activities, followed by the participation in scientific courses. Meanwhile, the number of scientific publications on the platform exceeded 12 thousand, and on top of them were the articles that published in scientific journals, where the number exceeded nine thousand research papers. In addition, 36 types of academic activities have been keyed in, including publishing books and participating in conferences and seminars. In conclusion, the researchers recommended that the awareness of joining the platform should be spread among Arabic-speaking researchers in all countries of the world to preserve the Arab identity, share scientific interests, and enrich Arabic content with scientific researches.
\end{abstract}

Keywords: ARID Platform, Bibliometrics, scientific platforms, Scholarly communication, online education. 


\section{الملخص}

بعد أربعة أعوام من افتتاح منصة "أُريد"، تجاوز عدد المستخدمين فيها عنبة (44) ألف مستخدم ناطق باللغة العربية

من مختلف دول العالم، وتعدّ "أُريد" أول منصة رقمية عربية تخدم البحث العلمي بطريقة مواكبة للتطور التقني مما جعل من الوصول للأبحاث العلمية في متناول الجميع. وتهذف الدراسة الى التعريف بمنصة اريد بلغة الارقام لنقل صورة احصائية للعلماء و الخبر اء والباحثين عن المنصة وكيفية الاستفادة من هذه التجربة وتحليل المعطيات في منصات رقمية تخدم اللغة العربية. وقد توصلت الدراسة الى نتائج عدة أهمها: أن أعداد المستخدمين في منصة أريد في ارتفاع مستمر، وتتفاوت اعدادهم بين مختلف الدول و الجامعات، وأن المنصة تضم تجمعاً واسعاً من مختلف التخصصات أبرز ها تخصصات العلوم التربوية والعلوم و الآداب و العلوم السياسية، وتضم عدداً كبيرًا من حملة الثهادات العليا (الماجستير والدكتور اه)، إذ بلغ عددهم نحو ثمانية آلاف مستخدم، وتتصدر المشاركة في المؤتمرات قائمة الانشطة الاكاديمية، ثم تليها المشاركة في الدورات العلمية، كما تجاوز عدد المنشور ات العلمية في المنصة (12) ألف منشور، وتأتي في مقدمتها المقالات المنشورة في المجلات العلمية حيث بلغ عددها نحو تسعة آلاف ورقة بحثية. ومن حيث الأنشطة الأكاديمية، فقد تم التوصل إلى (36) نمطًا من الانشطة الاكاديمية من ضمنها: تأليف الكتب و المشاركة في المؤتمرات و الندوات. ونوصي بضرورة نشر ثقافة الانضمام الى المنصة بين الباحثين الناطقين باللغة العربية في جميع دول العالم للحفاظ على الهوية العلمية العربية والارتقاء بالاهتمامات العلمية وإثراء المحتوى العربي بالبحوث العلمية ولاسيما التخصصات البينية. الكلمات المفتاحية : منصة أُريد، الدراسات الببليومترية، المنصات العلمية، التو اصل العلمي، التعليم عن بُعد. 


\section{1. المقدمة}

مع انتشار استخدام الانترنت والاجهزة الذكية، دخل مفهوم التعليم الالكتروني مؤخر اً إلى العالم العربي، والذي من مميز اته انه لا يتطلب تو اجد المعلمين والمتعلمين في مكان معين، وله قو اعده الخاصة به، كما قد ظهر ايضاً مفهوم المنصات العلمية، و التي تهدف اللى اتاحة الفرصة للباحثين للتعريف بأنفسه و انتاجهم العلمي، وتسهيل التو اصل العلمي بين الباحثين، واتاحة الولوج المفتوح Open Access الى المنشور ات العلمية بحرية ودون قيود.

و المنصات الرقمية platforms هي أحد أبرز أساليب إيصال المعلومات ومصادر هاوخدماتها إلى المستفيدين المحتملين منها، وذللك من خلال نقط وصول واحدة single-entry point. وتلعب المنصات اليوم دورًا كبيرًا في إثراء العمليات التعليمية و البحثية، كما قدمت قيمة مضافة للاتصال علمي بين الباحثين حيث ألغت الفوارق بين كل من الاتصال الرسمي وغير الرسمي و الذي كان شائعا في بيئة المعلومات الورقية. ونحاول في هذه الدر اسة إلقاء الضوء على أنشطة منصة أريد ARID في السنوات الأربع الأولى من إنشائها (أي بين عامي 2016-2020)، وبعض ملامحها وخصائصها البنيانية، ودلالات ذلك بالنسبة للاتصال العلمي في المجتمع العربي.

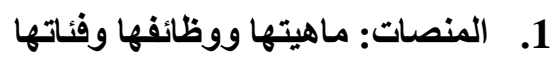

المنصة بحسب تعريف محمد (2019) "عبارة عن بيئة تعليمية تفاعلية توظف تقنية الويب وتجمع بين مميزات أنظمة إدارة المحتوى الإلكتروني وبين شبكات التواصل الاجنماعي الفيس بوك، وتويتر وتمكن المعلمين من نشر الدروس ووضع الو اجبات وتطبيق الإنشطة التعليمية، والاتصـال بالمتعلمين من خلال تقنيات متعددة، تقسمه إلى مجمو عات عمل، وتساعد على تبادل الافكار ". اما في دراسة السويدي (2018) فقد تم تعريف المنصة على أنها: "مجموعة من الثبكات والمواقع على الإنترنت يستخدمها الباحثّن و العلماء و الأكاديميون كلّ في مجال تخصصه، بقصد النشر و المشاركة والاطلاع وتحميل البحوث والأوراق و الدر اسات والكتب العلمية، وأيضا من أجل التعاون وتبادل الخبرات والتجارب لتطوير البحث العلمي". اما مفهوم الاتصال العلمي فيقصد به " نشاط يهدف إلى نقل وتداول المعرفة العلمية بين الباحثين وغير هم، وهي عملية تتم على مستويين: يمثل المستوى الأول الإتصال بين العلماء والفئات الواسعة من الناس، ممن لديهم القدرة على إستبعاب الخطاب العلمي الموجه لهم، أما المستوى الثاني فيمثل كل فعل إتصالي يتم بين باحثين و علماء، وأساتذة داخل نظام مغلق يتبنى أسلوباً 
علمياً " (نذير, 2010). أما عبد المجيد صالح بوعزة (2009) كان له تعريف مختصر للإتصال العلمي وهو: "عملية تبادل ونشر

$$
\text { البحوث العلمية ونتائجها فيما بين العلماء". }
$$

في حين بمكن تعريف الوصول الحر بأنه إطلاق الإنتاج الفكري و إتاحته على الإنترنت، والسماح لأي من المستفيدين بالاطلاع، والتحميل ، و النسخ، والتوزيع، والطباعة، والبحث، أو الربط بالنصوص الكاملة لتلك المقالات، وتتبعها بغرض التكثيف، ونقلها كبيانات إلى البرمجيات المختلفة، أو الإفادة منها لأي غرض من الأغراض (فراج, 2017) وتختلف مكونات المنصات اختلافًا كبيرًا باختلاف وظائفها وفئاتها وجمهور المستفيدين منها.و وعلى سبيل المثال، تستقل بعض المنصات ببعض أنماط المعلومات؛ فمنها ما يختص بتطبيقات الهو اتف الخلوية، أو الملفات المرئية الثابتة (الصور ) أو المتحركة (ملفات الفيديو)، ومنها ما يختص بالبيانات البحثية research data، ومنها ما يشتمل على جميع مصادر المعلومات المحتملة.

كما تختلف المنصات الرقمية باختلاف أهدافها؛ فمنها المنصات التعليمية (كأكاديمية خان Khan Academy، و البحثية (مثل بو ابة الباحثين Researchgate) و الباحث العلمي لجوجل (Google Scholar) ، والمهنية (مثل لنكدإن LikedIn)، و الاجتماعية (كثبكات التواصل الاجتماعي على سبيل المثال)، ... إلى آخره. ومن المنصات ما يجمع بين عدة أهداف في نفس الوقت. و على سبيل المثال، فبالرغم من أن فيسبوك هي منصة اجتماعية في الأساس، إلا أنها غدت تستخدم أيضًا - خاصة في الأعوام الأخيرة ـ للأغر اض التعليمية و البحثية بكفاءة بالغة. ومن ناحية التخصصات الموضو عية، كثيرة هي المنصات العامة في تغطيتها الموضو عية، كما يوجد عديد من المنصات التخصصية في موضوع محدد من موضوعات المعرفة البشرية؛ مثل العلوم الطبية، أو التربوية، أو الحاسبات الإلكترونية، ... إلخ. وبالر غم من أن معظم المنصات البحثية تخدم جميع فئات الباحثين على اختلاف تخصصاتهم، إلا أن هناك من المنصات ما يتوجه منها لفئة محددة منهم كالمحكمين reviewers على سبيل المنال. Asadullah, ) وبناء على مر اجعة علمية مكثفة للإنتاج الفكري المنشور في هذا الموضوع بالإنجليزية، توصل البعض (Faik, \& Kankanhalli, 2018 تتصل بنمط الحوكمة، وأخيرًا رابعة تتصل بنمط الملكية (جدول 1). 


$$
\text { جدول (1): فئات المنصـات الرقمية }
$$

\begin{tabular}{|c|c|c|c|}
\hline & $\begin{array}{c}\text { Dimension of } \\
\text { Categorization }\end{array}$ & Major types & Examples \\
\hline \multirow{9}{*}{$\begin{array}{c}\text { Digital } \\
\text { Platform } \\
\text { Categories } \\
\text { from } \\
\text { Existing } \\
\text { Literature }\end{array}$} & \multirow[t]{3}{*}{ Business model } & $\begin{array}{l}\text { Integrator platform } \\
\text { model }\end{array}$ & $\begin{array}{c}\text { Apple iOS; } \\
\text { InnoCentive.com; } \\
\text { Google Android }\end{array}$ \\
\hline & & Product platform model & $\begin{array}{l}\text { Linux; Cloud computing } \\
\text { initiatives }\end{array}$ \\
\hline & & $\begin{array}{c}\text { Multisided platform } \\
\text { model }\end{array}$ & Facebook; eBa, Alibaba \\
\hline & \multirow[t]{2}{*}{ Interaction mode } & Collaborateive platforms & Threadless.com; Wikipedia \\
\hline & & Competitive platforms & $\begin{array}{c}\text { TopCoder; Video games on } \\
\text { consoles }\end{array}$ \\
\hline & \multirow{2}{*}{$\begin{array}{l}\text { Governance } \\
\text { mode }\end{array}$} & Opened platforms & Linux; Wikipedia \\
\hline & & Closed platforms & Apple iOS; Google Android \\
\hline & \multirow[t]{2}{*}{$\begin{array}{l}\text { Ownership } \\
\text { Structure }\end{array}$} & Property based platform & $\begin{array}{c}\text { Sony (game consoles); } \\
\text { Microsoft platforms }\end{array}$ \\
\hline & & $\begin{array}{l}\text { Open source-based } \\
\text { platform }\end{array}$ & Linux; $\mathrm{R}$ \\
\hline
\end{tabular}

و تقدم المنصات الرقمية، على اختلاف أشكاللهاوفئاتها، عديدًا من خدمات المعلومات، مثل التو اصل الإلكتروني، و التعليم

الرقمي، وتحميل الملفات ونشر ها وتقاسمها بين أعضاء المنصة، والبحث عن المعلومات المحتو اة فيها؛ وذلك بهذف دعم أواصر

$$
\text { التو اصل العلمي بين الباحثين، وتطوير النشاط العلمي في التخصصات الموضو عية المختلفة. }
$$

وبالرغم من تو افر كثير من المنصات الرقمية في الفئات السابق الإشارة إليها، في معظم لغات العالم الحية، إلا أن

الباحث الناطق بالعربية ظل مفتقدًا لمنصة عربية علمية أصيلة يمكنه الحضور و التواصل العلمي من خلالها وتبادل المعلومات و الأفكار فما بينه وبين نظر ائه من الباحثين، و هو ما حاولت أن تقوم به منصة أريد في السنوات الماضية بحول الله وعونه وقوته.

$$
\text { 2. }
$$

تم افتتاح منصة "أُريد" يوم 25 أبريل 2016 كأول منصة رقمية للباحثين و العلماء و الخبر اء الناطقين بالعربية، في جامعة الملايا في كو الالمبور - ماليزيا. و الهدف العام للمنصة هو جَمْعُ الباحثين الناطقين بالعربية في دَائرٍٍِ عِلميةٍ واحِةٍة حيث يساعد ذلك الباحثين أصحاب التخصصات المتشابهة و المتقاربة على التو اصل فيما بينهم ومتابعة بعضهم البعض لغرض مشاركة الاهتمامات العلمية، ونوفير فرصة عرض أعمالهم وسيرهم الذاتية وجهودهم العلمية في صفحة شخصية خاصة، و اعطاء رقٍٍ 
مُعَرٍِّ خاص بكلِّ باحثٍ لتجنب مشاكل تداخل وتشابه أسماء الباحثين مما قد يؤدي إلى ضياع حقوق الباحث ("ماهي منصة

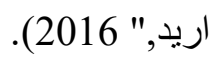

كما تهدف المنصة إلى تعزيز حضور الباحثين الناطقين باللغة العربية في العالم الافتر اضي للمساهمة في تطوير البحث

$$
\text { العلمي (سلمان, 2019)، و إعداد نظام تصنيف لكلِ باحثٍ ومُؤسسةٍ أكاديميةٍ على غِر ار التصانيفِ العالميةِ المعتمدة. }
$$

وتعد منصة أُريد شبكة اجتماعية أكاديمية، تخدم الباحثين الناطقين باللغة العربية، وتتيح مشاركة الأنشة الأكاديمية

مثل مشاركة الأوراق و البيانات وبالتالي فإنها تدعم سياسات الوصول الحر. كما ان زيادة النسخ الالكترونية للبحوث تساعد في

زيادة إمكانية الاقتباسات لهذه البحوث كما كثفت عنه إحدى الدراسات ( \&rahimy, Mehrad, Setareh, \&

.(Hosseinchari, 2016

إضافة إلى ذلك، يمكن للباحثين من متابعة أقرانهم المتخصصين في المجال نفسه ومعرفة عدد متابعي صفحاتهم. كما أنها تتيح نشر أسئلة عامة على هذا التجمع الافتراضي و إمكانية الاجابة عنها، وتمكن الجامعات من البحث عن أعضاء طاقم تدريسي جدد في كافة التخصصات.

\section{3. أهداف الدراسة}

تهدف هذه الدر اسة إلى محاولة التعرف على بعض الخصائص البنيانية لمنصة أريد كمنصة بحثية وتعليمية للباحثين

$$
\begin{aligned}
& \text { الناطقين بالعربية. وبصفة خاصة تهدف هذه الدر اسة إلى التعرف على: } \\
& \text { • التطور الزمني لحضور الباحثين على المنصة، و التوزيع الجغر افي لهؤلاء الباحثين. } \\
& \text { • أبرز الجامعات و المؤسسات الأكاديمية حضورًا على المنصة. } \\
& \text { • الأنشطة الأكاديمية للباحثين المسجلين بالمنصة، و أكثر ها تو اترًا عن غير ها. } \\
& \text { • الاهتمامات التخصصية للباحثين، و أكثر هذه الاهنمامات حضورًا على المنصة. } \\
& \text { • الشهادات الأكاديمية، و المهار ات العلمية، و غير ها من الملامح ذات الصلة لمنصة أريد. } \\
& \text { • بعض الأنظمة التي ابتكرتها المنصة، مثل نظام منح الأوسمة، ونظام عليم للتعليم الإلكتروني. }
\end{aligned}
$$




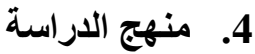

تعتمد هذه الدر اسة على المنهج الوصفي التحليلي، وبصفة أساسية على بعض أساليب القياسات الور اقية (البليوجر افية) Rehn, Kronman, Gornitzki, Larsson, \& Wadskog, 2008) Bibliometrics و هي تللك الأساليب الكمية التي تعني في الأساس بقياس خصائص مصادر المعلومات في أي مجال علمي تخصصي، وتحليلها وتفسير ها، وبيان عناصره الأكثر نشاطًا و إنتاجًا من غيرها. وتهدف الببليومتريقا، على العموم، إلى تقييم آليات البحث العلمي المتخصص، وتوفير البيانات اللازمة لمتخذي القرار و القائمين على رسم السياسات العلمية في المجتمع (فراج, 2016). وتكثــف مر اجعة الإنتاج الفكري أن الباحثين الذين اهتموا بدراسـة اتجاهات البحث في الإنتاج الفكري وخصـائصسه، اعتمدوا في الأسـاس على اسـتخدام الأسـاليب البيليومترية Bibliometric techniques في تحليل البيانات. كما تكثـف هذه المر اجعة أن هذه الأسـاليب هي أفضـل المناهج المسـتخدمة في هذا النوع من الدراسـات، و الذي يعد مسـتخدماً بكثافة في قباس الإنتاج الفكري في التخصصات المختلفة، وبخاصة في العقود الأربعة الأخيرة.

و الو اقع أن تللك الأســاليب البيليومترية و الدر اسـات التحليلية التي تتبني عليها، طريقة شـائعة لقياس إنتاجية البحوث وخصائصها في التخصصات العلمية المختلفة؛ تلك البحوث الصادرة في هيئة رسائل جامعية (فراج, 2015)، أو المنشورة في الدوريات العلمية (Mowafi, 2012)، أو الناتجة عن الأفراد (Kademani, 2001) أو المؤسـســـات أو المجتمعات الأكبر حجماً كالدول والأقاليم الجغر افية على سبيل المثال (Kirby, 1991). وفيما يتصل بالبيانات التي تمّ الاعتماد عليها في هذه الدر اسة، فقد تم استخر اجها من قاعدة بيانات "منصة أُريد" بتاريخ 30 مايو 2020، وتم هنا استخدام التحليلات الإحصائية و البيليومترية الملائمة بما يحقق أهداف الدراسة، كما تم استخدام برنامج Excel

\section{5}

من الطبيعي أن تختلف الدراسات السابقة في هذا الموضوع اختلافًا بينًا في أهدافها ونطاقها و أساليبها المنهجية. وقد أفادت إحدى الدر اسات التي انصبت على اليابان، وبصفة خاصة بناء على مدى استخدام Academia.edu و ResearchGate ، إلى أنه بالر غم من المكانة الرفيعة التي يحتلها نظام التعليم هناك، إلا أن المكانة الدولية للباحثين تشهد انخفاضًا ملحوظًا ويرجع ذلك نسيًا إلى ضعف حضور الباحثين على المنصات أو الثبكات الاجتماعية الأكاديمية. ويرى أصحاب الدراسة أن الحواجز 
اللغوية والثقافية تقدم أحد التفسير ات المحتملة لاتجاهات الاستخدام، كما أن هناك حاجة لمزيد من التدريب للباحثين في اليابان على الخصائص المميزة للمنصات الرقمية. وقد حاولت إحدى هذه الدراسات (Martín-Martín, 2018) إستكثاف مدى تبني الباحثين في قياسات المعلومات

لبعض أثهر المنصات العلمية والبحثية وهي Google Scholar Citations, ResearcherID, ResearchGate, ،endeley and Twitter) القياسات الناتجة عن هذه المنصات تقع في فئتين رئيستين هما: القياسات الدالة على مدى الارنباط والتفاعل (وهي التي تتصب على عدد المتابعين followers، و القياسات الدالة على مدى الإفادة من المعلومات و هي بدور ها تتقسم إلى نمطين؛ يختص أو لاهما بمدى القراءة و الاطلاع، بينما ينصب الثاني على قياسات الإشار ات المرجعية. كما حاولت دراسة أخرى الكثف عن مدى الإفادة من منصة Google Scholar Citations من قبل الباحثين في مجال المكتبات والمعلومات في باكستان، وتوصلت الدر اسة إلى أن إجمالي حضور هؤلاء الباحثين لهذه المنصة يعد منخفضًا بصورة نسبية، كما أن هذه النسبة لم تعمل على تعظيم الفرص التي توفر ها المنصة بغرض التألق البحثي و العلمي على الإنترنت .(Ali \& Richardson, 2019) واعتمادًا على منصة ResearchGate ، حاولت إحدى الدراسات فحص أحد القياسات الحديثة لهذه المنصة وهي ما تسمى بالاهتمامات البحثية Research Interest. ويعتمد هذا المقياس على نظام للنرجيح فيما بين الاستشهادات المرجعية، و التوصيات، و عدد واقعات النصوص الكاملة، وغير ها من واقعات القراعة لدى منسوبي هذه المنصة العالمية ( Copiello,

واعتمادًا على منصة ResearchGate أيضًا، حاولت إحدى الدراسات الكثف عن مدى العلاقة بين عدد النصوص الكاملة المرفو عة لباحث معين على المنصة، ومعدلات قر اءة هذه النصوص، وما يعرف بمؤشر (آر جي) RG Score. و أسفرت الدر اسة عن أن النتائج المستخرجة من مجموعة البيانات محل البحث تؤدي إلى نتائج منضاربة. وهو ما يحتاج إلى مزيد من الدر اسات في هذا المضمار (Copiello \& Bonifaci, 2019). 


\section{1/7 التوزيع الجغرافي والزمني لمستخدمي المنصة}

بلغ عدد مستخدمي المنصة (44,597) باحثا و عالما وخبيرا، حنى 30 مايو 2020، من (103) دول حول العالم.

ويوضح النكل (1) نمو عدد المستخدمين خلال السنوات الماضية، ومنه يتضح زيادة عدد هؤلاء المستخدمين بإطر اد من فترة زمنية إلى أخرى. أما الثكل (2) فيوضح التوزيع الجغر افي لعدد المسجلين في المنصة وذلك بحسب كل دولة.

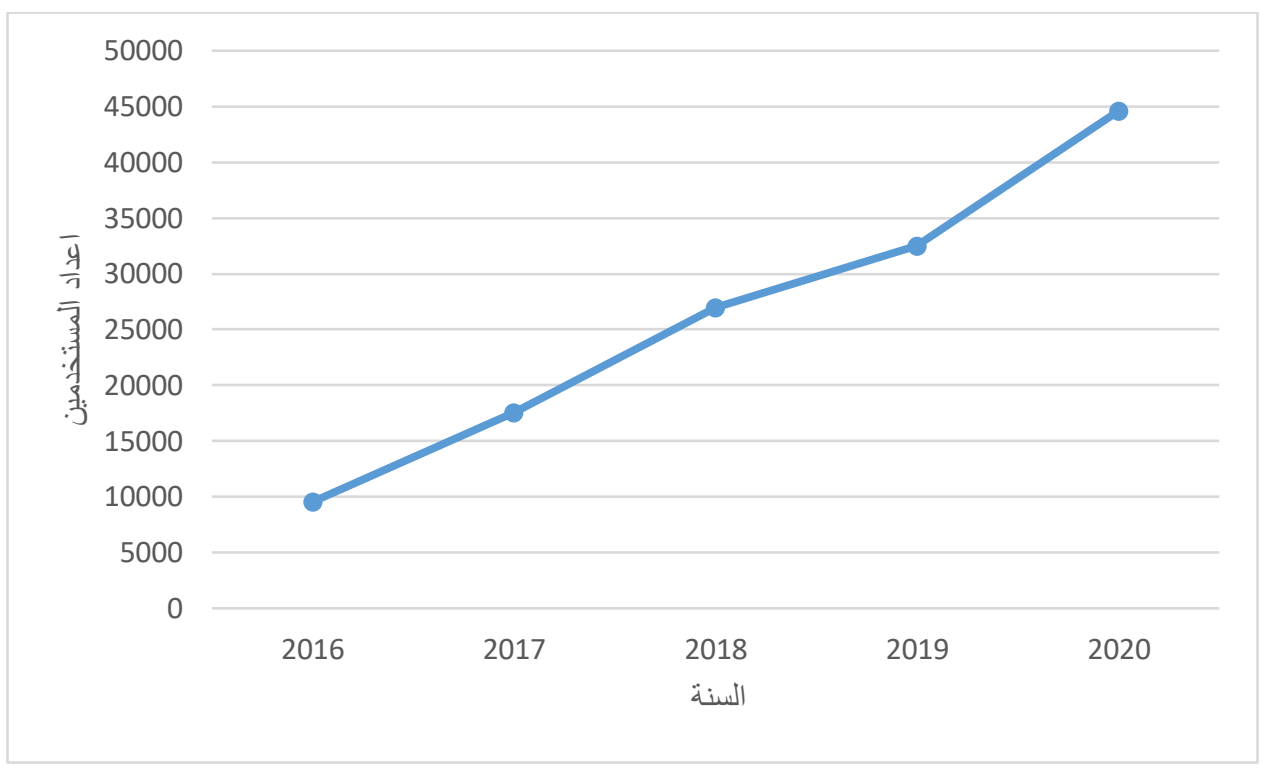

الثكل (1): التطور الزمني لعدد المستخدمين للمنصة (2020-2016) 


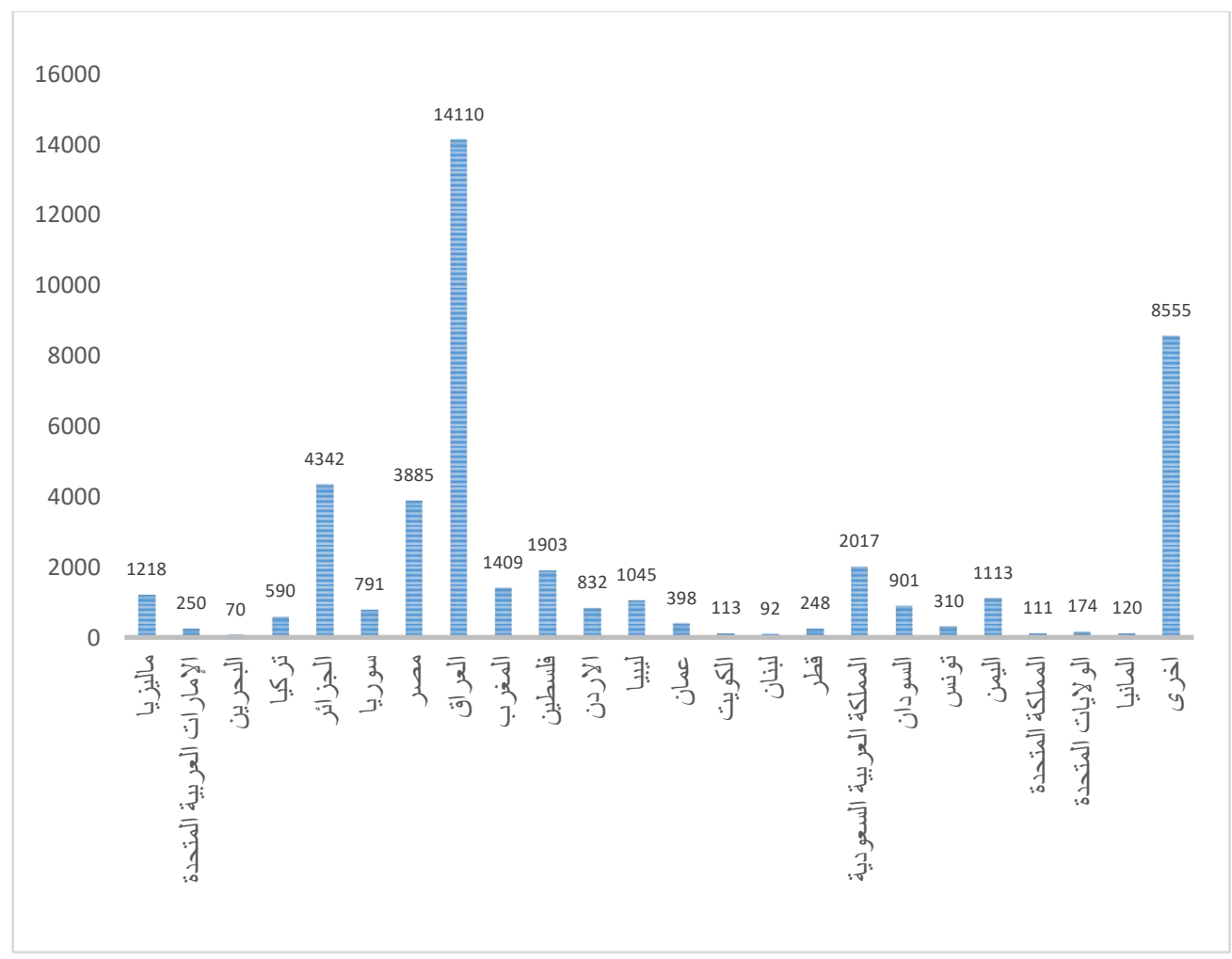

شكل (2): التوزيع الجغر افي للباحثين المسجلين في المنصة (مايو 2020)

ويلاحظ هنا أن العراق تبوأ المرتبة الاولى في عدد المسجلين في المنصة بو اقع 14,110 باحثين (حوالي 31.6\%) أي ما يقرب من ثلث مجموع الحاضرين على المنصة، وذلك بسبب نوجيهات وزارة التعليم العالي العر اقية ورؤساء الجامعات بحث الأكاديميين على التسجيل في المنصة و الإستفادة من المو اد العلمية والدورات المقامة فيها، واقامة نسخة من المحفل العلمي السادس فيه، وكذلك جهود اللجنة التنسيقية الفرعية في العراق.

وتأتي الجز ائر في المرتبة الثانية برصيد 4,342 باحثا (حو الي 9.7\%)، ويعزى ذلك الى اقامة نسخة من المحفل العلمي

$$
\text { الدولي السادس (أحد النشاطات العلمية للمنصة) في الجز ائر في شهر أبريل } 2020 .
$$

أما المرتبة الثالثة فحازت عليها مصر بعدد 3,885 باحثا (حوالي 8.7\%)، ثم السعودية في المرتبة الرابعة 2,017 باحثا (حوالي 4.5\%)، ثم فلسطين في المرتبة الخامسة 1,903 باحثين (حوالي 4.2\%). ويوضح شكل (3) التوزيع الجغرافي للمسجلين في العالم. 


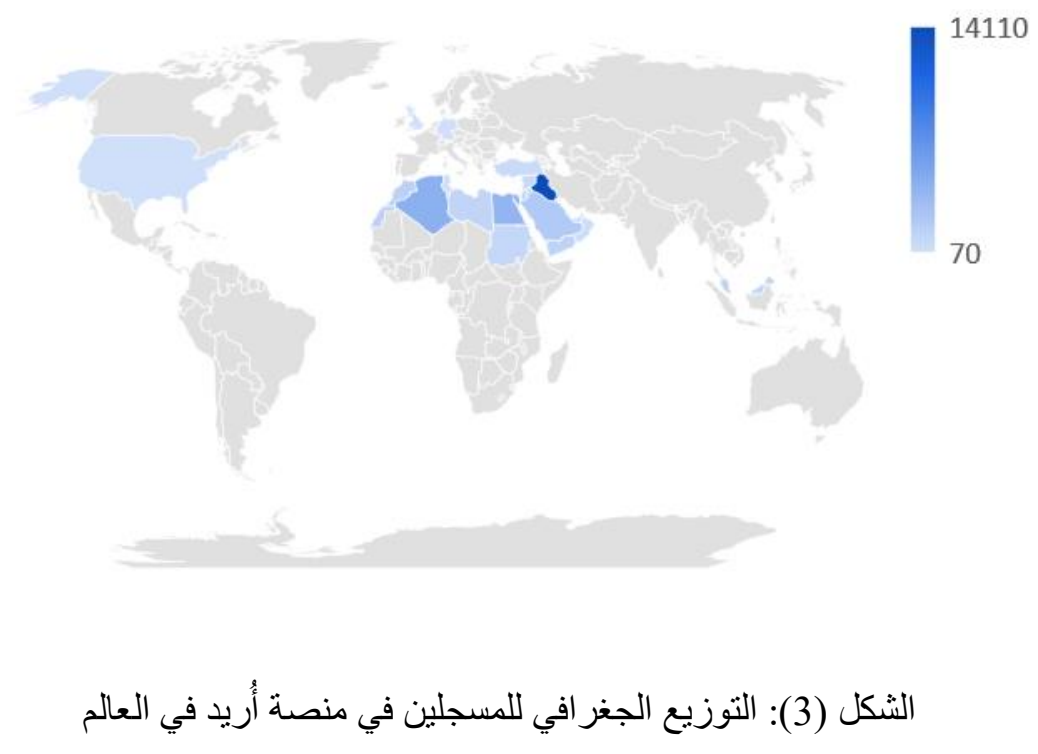

2/7 أبرز الجامعات حضورًا على المنصة

ينتمي جميع المسجلين في المنصة الى (18,236) جامعة و مركز بحثي ومؤسسة اكاديمية موزعة على كثير من دول العالم. ويوضح جدول (2) أسماء الجامعات الخمس الأُولى في الدول الخمس الأُولى مع الإشارة إلى عدد المسجلين في كل جامعة. 


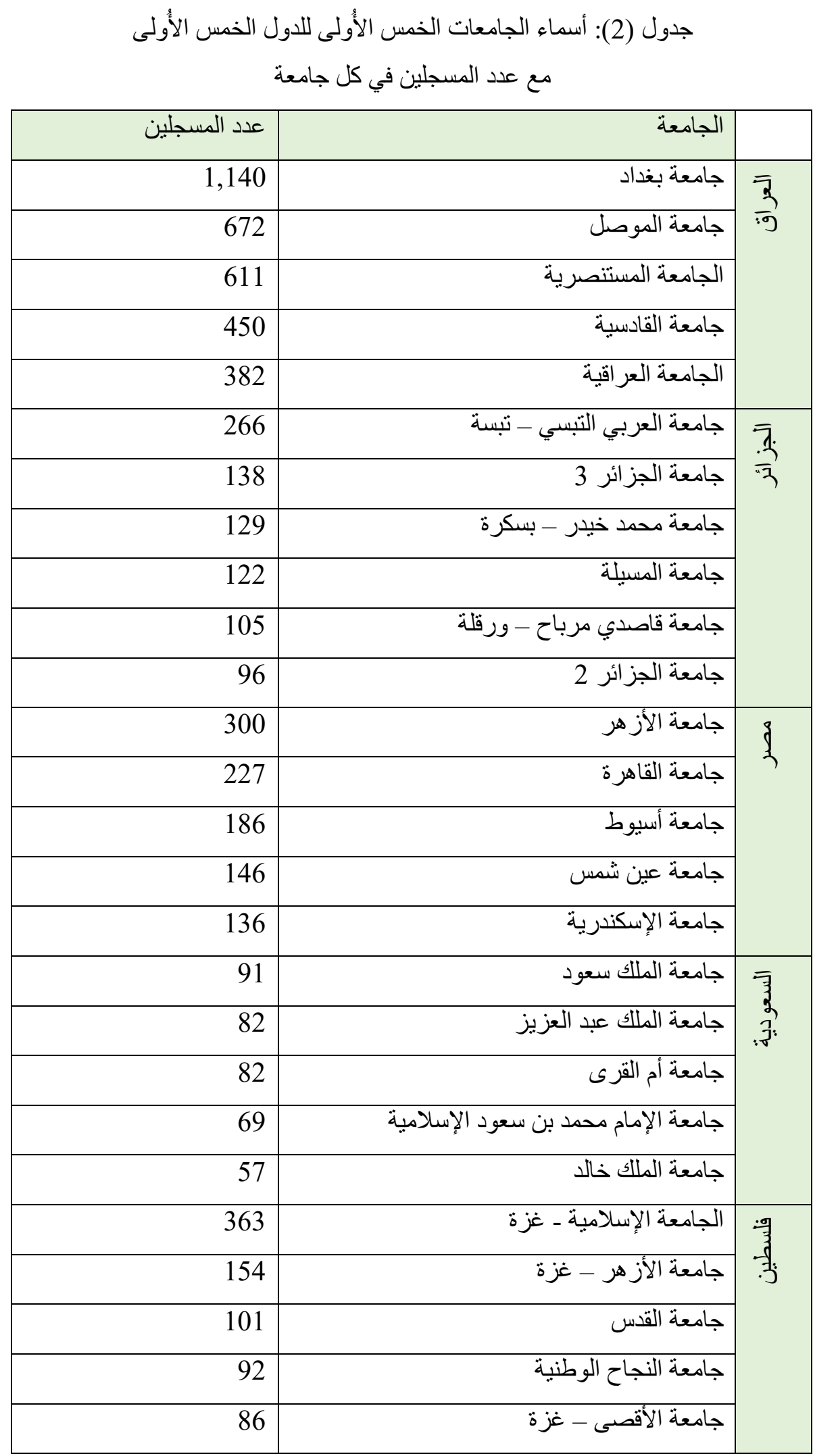


ونلاحظ في جدول (2) أن جامعة بغداد تتصدر الجامعات العر اقية في عدد المسجلين، أما في الجزائر، فتتصدر جامعة

العربي التبسي - تبسة الجامعات الاخرى في عدد المسجلين في المنصة وربما كان السبب أن هذه الجامعة كانت أحد الرعاة للمحفل العلمي الدولي السادس. ثم تأتي جامعة الازهر على رأس الجامعات المصرية وهي أحد أعرق الجامعات العربية و الإسلامية كما هو معلوم، وتحتل جامعة الملك سعود المرتبة الأولى في المملكة العربية السعودية وهي إحدى أبرز الجامعات العربية في التصنيفات الدولية للجامعات University rankings في السنوات الأخيرة، وأخير اً تحتل الجامعة الإسلامية ـ- غزة المرتبة الأُولى بين جامعات في فلسطين.

\section{3/7 - 3/7 الأنثطة الأكاديمية}

تضمنت الأنشطة الأكاديمية الموجودة في المنصة (36) نوعاً من ضمنها تأليف الكتب أو كتابة فصول من كتب و المشاركة في المؤتمر ات و غير ها. أما المدخلات المسجلة من قِبل أعضاء المنصة فقد بلغت $(25,863)$ مدخلاً. ويوضح الثكل (4) أعداد المُدخلات لأعلى (15) نشاطا أكاديميا.

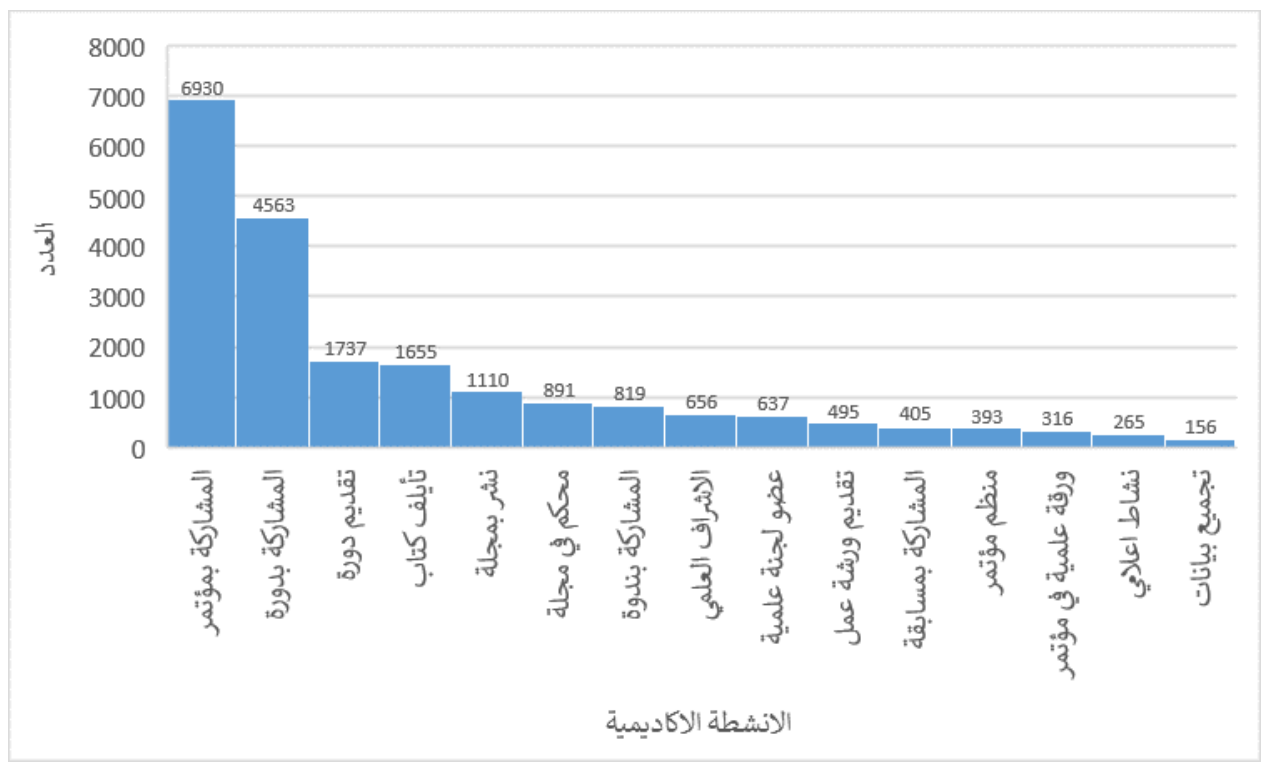

الثنكل (4): أعداد المُخخلات لأبرز (15) نثاطا أكاديمياً. 
ونلاحظ من خلال الثكل (4)، أن المشاركة في المؤتمرات تتصدر جميع الأنشطة الأكاديمية (6,930)، تليها الندوات

العلمية (4,563)، ومن المُرجح أن السبب في ذلك هو سهولة المشاركة في هذا النوع من الأنشطة مقارنة بغيره. بالإضافة الى

ذلك، يُلاحظ أن ارتفاع عدد المدخلات في مجال تأليف الكتب (1,655 هُدخلاً) و هذا يعكس إقبال الباحث العربي على الإبداع الفكري وقدرته على التأليف و الكتابة. وليس من الثائع - مثلا - مشاركة الإنتاج الفكري في شكل فصول الكتب و التي بلغت 60 مدخلاً، وربما يعود ذلك لأسباب تقنية وتتظيمية بحتة. من ناحية أخرى، تدل نتائج هذا المبحث بصفة عامة أن ثقافة المجموعات البحثية والتعاون العلمي المشترك غير شائعة بين العلماء و الخبر اء والباحثين الناطقين بالعربية، وأن التأليف الفردي هو الغالب؛ هذا بالر غم من أن النشاط العلمي في العالم المعاصر يقوم على الفرق البحثية و التأليف المشترك. ويقصد بالمجموعات البحثية "مجمو عات تُعنَى بالعمل البحثي المشترك بين عددٍ من الباحثين، من أجل إنجاز أبحاث متميّزة كماً ونوعاً وذات فائدة للمجتمع، وتتكون المجموعة البحثية من مجموعة من الباحثين من تخصصات متتو عة و متكاملة و إمكانات وخبرات بحثية، تضمن الجودة وكثافة الإنتاج، إلى جانب باحثين ناشئين، وطلاب دراسات عليا؛ لإكسابهم المهار ات البحثية، و التمرُّ" ("المجمو عات البحثية," 2020).

4/7 التخصصات العلمية

ومن حيث التخصصات العلمية التي وسمت الاهتمامات الموضوعية للباحثين، فقد بلغ عدد المُدخلات فيها (19,893)

$$
\text { تخصصا. ويوضح شكل (5) التخصصات العلمية ونصيب كل منها في المنصة. }
$$




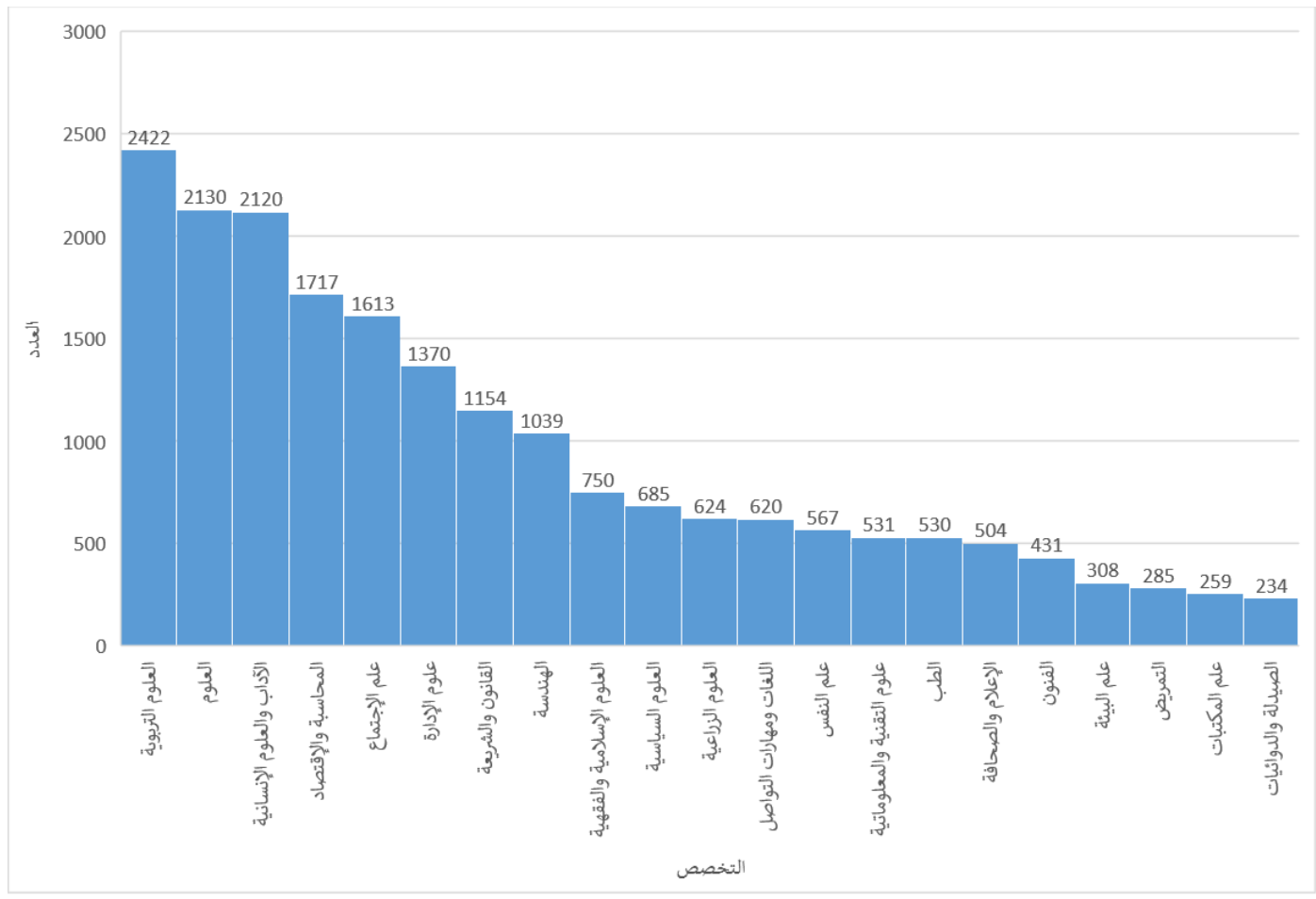

$$
\text { الشكل (5): التخصصات الموضوعية و أعدادها في المنصة }
$$

وكما هو و اضح، هنالك تداخل بين بعض التخصصات الموضو عية، كما أن بعضها عريض للغاية منل الآداب و العلوم الإنسانية، وبعضها دقيق للغاية مثل علم البيئة. ويعكس ذلك سلوكيات الباحثين في وسم المصطلحات الدالة على تخصصاتهم الموضو عية. وتكثفف الجداول (من 3 إلى 6) عن طبو غر افية التخصصات الموضو عية للباحثين الحاضرين حاليًا على المنصة. ومن الو اضح (جدول 3) أن العلوم الاجتماعية هي أكثر التخصصات العريضة حضورًا على المنصة وذلك بنسبة تكاد تصل إلى نصف عدد المدخلات، بما يعني أن باحثي هذا القطاع - نسبيًا ــ أكثر نشاطًا من غيرهم في الحضور العنكبوتي عامة وعلى المنصات خاصة و على "منصة أريد" بصورة أخص. بينما تتقاسم العلوم الطبيعية والتطبيقية من جهة والعلوم الإنسانية من جهة أخرى النصف الآخر من مدخلات الباحثين على وجه التقريب. 


$$
\text { جدول (3): التخصصات الموضو عية العريضة في منصة أريد }
$$

\begin{tabular}{|c|c|c|c|}
\hline تر اكمي\% & $\%$ & عدد المدخلات & التخصص الموضوعي \\
\hline 45.9 & 45.9 & 9137 & العلوم الاجتماعية \\
\hline 74.4 & 28.5 & 5681 & العلوم الطبيعية و التطبيقية \\
\hline 99.9 & 25.5 & 5075 & العلوم الإنسانية و الفنون \\
\hline & 99.9 & 19893 & المجموع \\
\hline
\end{tabular}

$$
\text { جدول (4): تخصصات العلوم الاجتماعية في منصة أريد }
$$

\begin{tabular}{|c|c|c|c|}
\hline تر اكمي\%\% & $\%$ & عدد المدخلات & التخصص الموضوعي \\
\hline 26.5 & 26.5 & 2422 & التربية \\
\hline 45.3 & 18.8 & 1717 & الاقتصاد و المحاسبة \\
\hline 62.9 & 17.6 & 1613 & علم الاجتماع \\
\hline 77.9 & 15 & 1370 & الإدارة \\
\hline 85,3 & 7.4 & 685 & العلوم السياسية \\
\hline 91.5 & 6.2 & 567 & علم النفس \\
\hline 97 & 5.5 & 504 & الإعلام \\
\hline \multirow[t]{2}{*}{99.8} & 2.8 & 259 & المكتبات \\
\hline & 99.8 & 9137 & المجموع \\
\hline
\end{tabular}

وأكثر باحثي العلوم الاجتماعية حضورًا على "منصة أريد" هم باحثو العلوم التربوية. ويتجاوز باحثو ذلك التخصص، إضافة إلى الاقتصاد و علم الاجتماع و الإدارة، ثلاثة أرباع مجموع باحثي هذا القطاع على المنصة؛ بينما تمثل السياسة و علم النفس و الإعلام و المكتبات الربع الآخر. 
ARID International Journal of Informetrics (AIJI) VOL: 1, NO 1, July 2020

جدول (5): تخصصات العلوم الطبيعية و التطبيقية في منصة أريد

\begin{tabular}{|c|c|c|c|}
\hline تر اكمي\% & $\%$ & عدد المدخلات & التخصص الموضوعي \\
\hline 37.4 & 37.4 & 2130 & العلوم (عام) \\
\hline 55.2 & 18.2 & 1039 & الهندسة \\
\hline 66.5 & 10.9 & 624 & العلوم الزراعية \\
\hline 75.8 & 9.3 & 531 & علوم التقنية و المعلوماتية \\
\hline 85.1 & 9.3 & 530 & الطب \\
\hline 90.5 & 5.4 & 308 & علم البيئة \\
\hline 95.5 & 5 & 285 & التمريض \\
\hline \multirow[t]{2}{*}{99.6} & 4.1 & 234 & الصيدلة و الدوائيات \\
\hline & 99.6 & 5681 & المجموع \\
\hline
\end{tabular}

ولم يحدد أكثر من ثلث مجموع الباحثين في قطاع العلوم الطبيعية والتطبيقية تخصصهم الدقيق على وجه الدقة. ويمكن القول إن باحثي العلوم الهندية والزراعية والمعلوماتية والطبية هم أكثر باحثي هذا القطاع المسجلين بالمنصة. ولما كانت تخصصات هذا القطاع هي قاطرة التنمية في أي مجتمع، فإنه ينبخي بذل مزيد من الجهود لاستقطاب الباحثين المتخصصين فيه إلى المنصة للتعرف على أنشطتهم العلمية والبحثية، وإتاحة الفرصة لمزيد من التواصل العلمي فيما بينهم وبين أقرانهم من

جدول (6): تخصصات العلوم الإنسانية والفنون في منصة أريد

\begin{tabular}{|c|c|c|c|}
\hline تر اكمي\% & $\%$ & عدد المدخلات & التخصص الموضوعي \\
\hline 41.9 & 41.9 & 2120 & الآداب و العلوم الإنسانية (عام) \\
\hline 64.6 & 22.7 & 1154 & القانون و الثريعة \\
\hline 79.3 & 14.7 & 750 & العلوم الإسلامية و الفقهية \\
\hline 91.5 & 12.2 & 620 & اللغات و مهار ات التو اصل \\
\hline \multirow[t]{2}{*}{100} & 8.5 & 431 & الفنون \\
\hline & 100 & 5075 & المجموع \\
\hline
\end{tabular}


و عادة ما يُشار إلى العلوم الإنسانية - بما تشتمل عليه من الأديان و اللغات و الآداب و التاريخ و الحضارة ـ إلى أنها أبرز ما يشكل هوية المجتمعات البشرية. ولم يقم أيضًا أكثر من خُمسي باحثي هذا القطاع بتحديد تخصصاتهم بدقة، وإن كان يمكن القول إن باحثي العلوم الإسلامية و الثرعية هم الأكثر حضورًا على المنصة بنسبة تيد عن ثلث مجموع باحثي هذا القطاع.

\section{5/7 المنشور ات العلمية}

تنبغي الإشارة هنا إلى أنه يوجد قسم مستقل للمنشور ات العلمية يُحسب بشكل مستقل عن الأنشطة العلمية. وقد بلغ عدد

المنشورات العلمية (12,179) مادة. ويوضح الثكل (6) توزيع المنشورات العلمية في كل نمط من أنماط مصادر المعلومات. ونلاحظ أن أغلب المنشور ات كانت في المجلات العلمية والتي بلغ عددها (9103) بحوث، وذلك بنسبة تكاد تصل إلى ثلاثة أرباع المنشور ات جميعًا (حو الي 74.7\%). و هذا شيء طبيعي في ضوء أن الدورية العلمية هي القناة الرئيسة للاتصال العلمي في كثير

$$
\text { من تخصصات المعرفة البشرية (قاسم, 2020). }
$$

وتأتي المؤتمرات في المرتبة الثانية بين أنماط مصادر المعلومات برصيد $(1,211)$ بحثًا بنسبة حوالي عُشر مجموع

المنشور ات (9.9\%)، تليها الكتب برصيد 1,054 كتاباً أو ما نسبته حو الي 8.6\%. و هذه في الحقيقة هي بعض أبرز أنماط مصادر المعلومات في العالم المعاصر الذي نعيش. وتمثل بقية أنماط مصادر المعلومات أقل من 7\% من مجموع المنشورات المثبتة على المنصة، وإن كان من بينها ما يمثل أهمية بالغة في النشاط العلمي وبصفة خاصة في العلوم والتقنية مثل التقارير وبراءات الاختر اع والمعايير القياسية. ولا يمكن تفسير هذه النتيجة سوى ضعف النشاط العلمي العربي في هذه الأنماط بصفة عامة، أو ضعف الصادر من هذه الأنماط لدى الباحثين المسجلين في المنصة. 


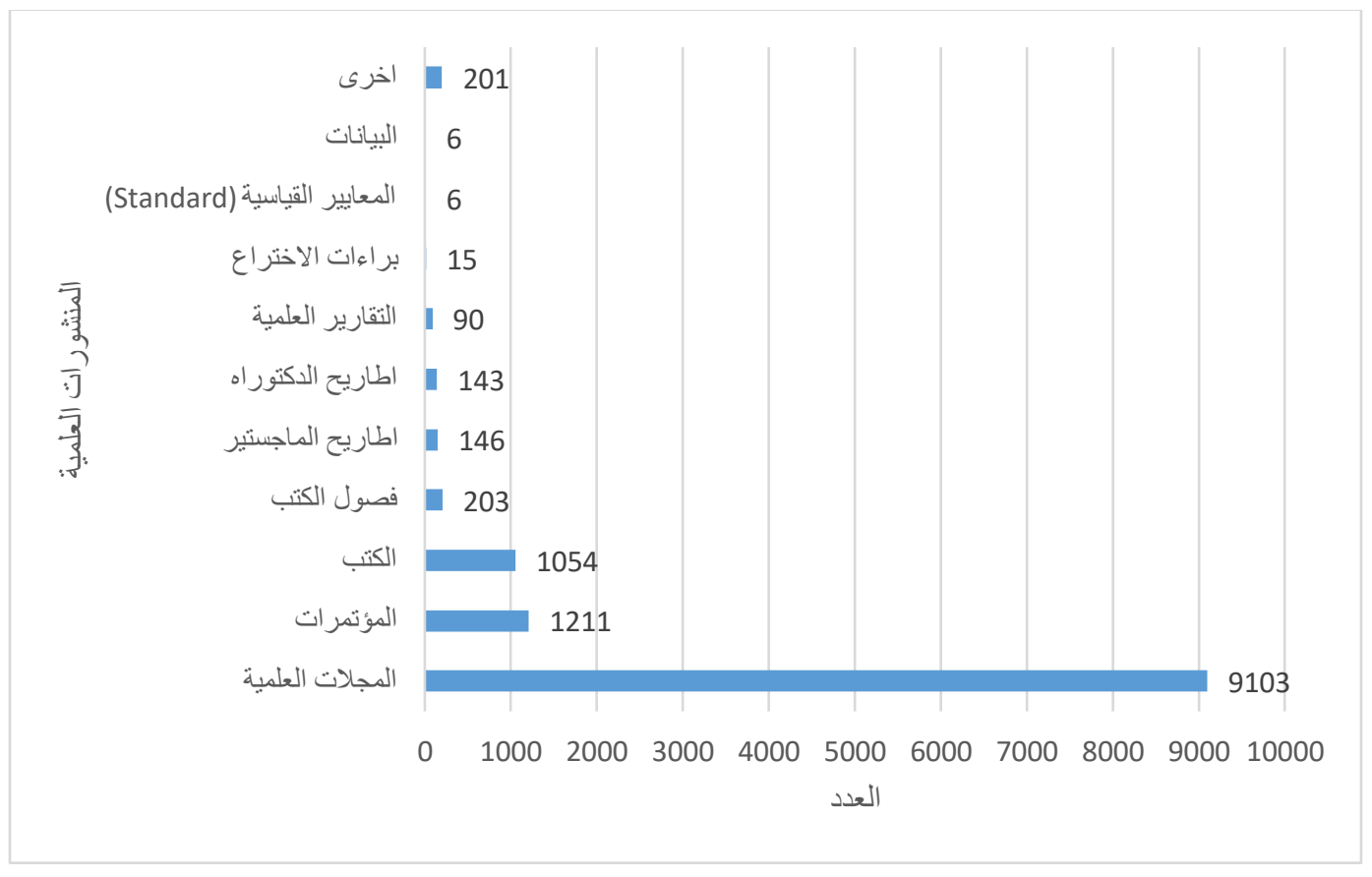

الثكل (6): المنشورات العلمية وأعدادها

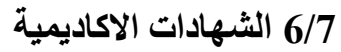

يوضح شكل (7) عدد المُدخلات لكل شهادة اكاديمية، ومنه يتضح أن عدد المُدخلات عن الثهادات الأكاديمية (4,419) (13,722)، مُدخلاً لثهادة الماجستير بنسبة حو الي ثلث مجموع الثهادات (32.2\%)، و (4,155) مُدخلاً لشهادة الدكتور اه بنسبة حو الي (30.2\%). أما شهادة البكلوريوس فقد بلغ عدد المُدخلات فيها (3,485) بنسبة حو الي (25.3\%). 


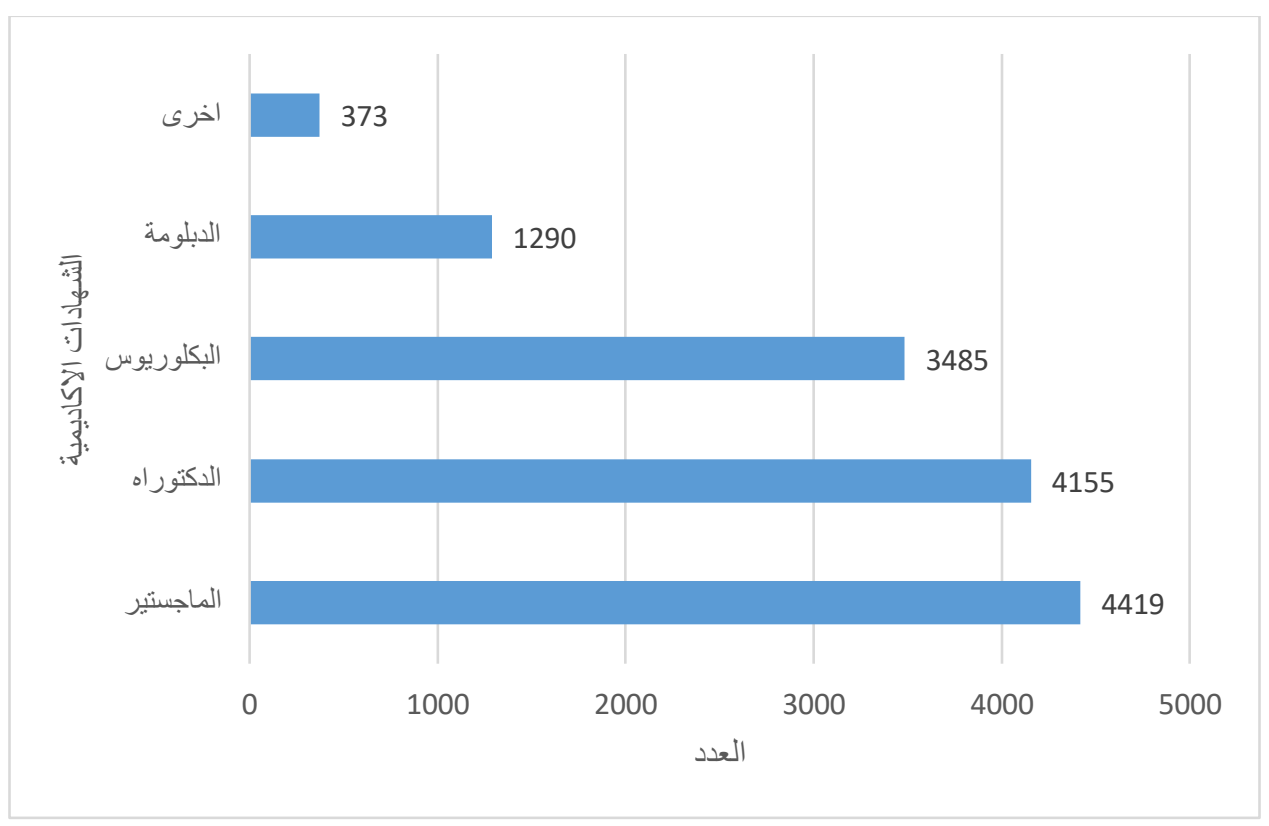

الثكل (7): الثهادات الأكاديمية و أعداد المُدخلات المُسجلة المسجلين في المنصة

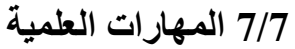

غزيرة للغاية هي المهار ات المسجلة في "منصة أريد" حيث بلغ عددها 1143 مهارة، بما يفيد بثراء الجدار ات العلمية و البحثية للباحثين المسجلين بالمنصة، ومن هذه المهار ات: البحث العلمي، والكتابة الأكاديمية، و التدقيق اللغوي، و إدارة المشاريع، و إدخال البيانات، و غير ها. وقد بلغ مجموع سجل المهارات التي أُدخلت في المنصة (18,921) مدخلا. ويوضح شكل (8) عدد المُدخلات المسجلة في كل مهارة. 


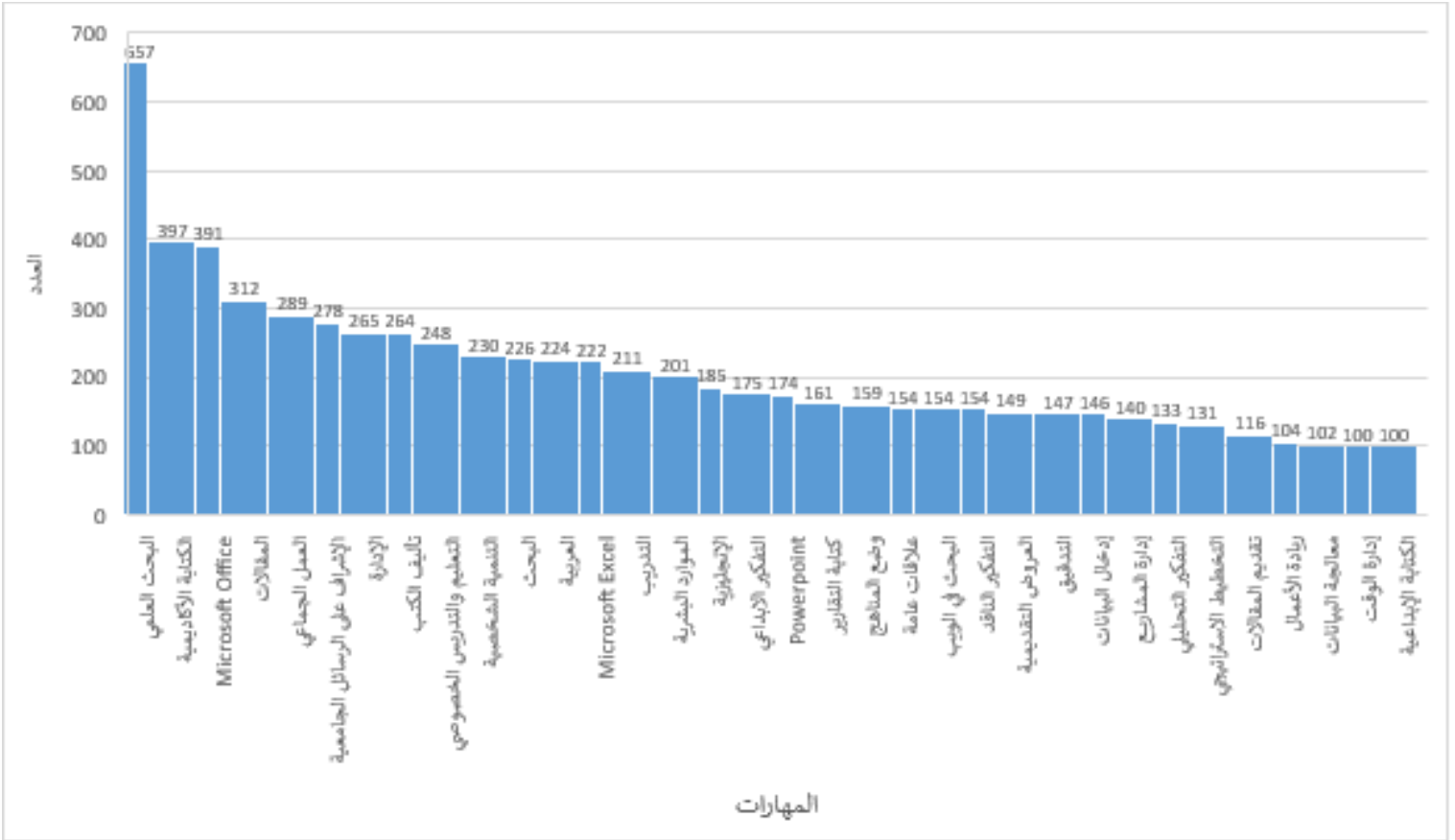

الثكل (8): المهار ات العلمية و أعداد المُدخلات المسجلة في كل مهارة.

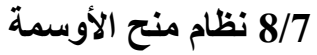

توفر المنصة 16 نوعاً من الأوسمة، تُنح للباحثن كنو عن التثجيع و التكريم بحسب التفاصيل الموضحة في المنصة.

و قد بلغ عدد الباحثين الذين حصلو ا على الأوسمة (3,850) باحثنا، و يبين الجدول (7) أنواع و أعداد الباحثين الذين حصلو اعلى كل وسام. 
جدول (7): أنواع الأوسمة المقدمة من المنصة

ورصيد الباحثين الحاصلين عليها

\begin{tabular}{|c|c|}
\hline عدد الباحثين الحاصلين على الوسام & نوع الوسـام \\
\hline 2,653 & وسام باحث مبادر \\
\hline 89 & وسام ناشِط في جامعة \\
\hline 160 & وسام مُبْدِع \\
\hline 27 & وسام ناشِيط دوليّ \\
\hline 13 & وسام إعلامي متميز \\
\hline 17 & مُحكّم \\
\hline 13 & وسام مُستشَّار \\
\hline 23 & وسام دَاعِم فضي \\
\hline 50 & وسام نَاثِرِ مُتميّز \\
\hline 262 & وسام الصفحة المتميزة \\
\hline 42 & وسام "مشروع عالم" \\
\hline 418 & ناشط في فعاليات منصة اريد \\
\hline 81 & باحث مبتدئ \\
\hline 2 & و وسام التحدي \\
\hline 3,850 & المجموع \\
\hline
\end{tabular}

9/7 نظام عليم للتعليم الأكتروني

مع بدء إنتشار جائحة كورونا وما رافقها من حظر صحي وأغلاق للمؤسسات التعليمية، تم استحداث نظام جديد داخل

المنصة أُطلق عليه "نظام عليم" وذلك لرفع الدورات والمحاضر ات التعليمية وإصدار الثهادات الخاصة بها بدءاً من تاريخ 1 مارس- آذار 2020، وذلك لِدعم التعليم عن بُعد للناطقين باللغة العربية. وقد بلغ عدد المحاضر ات في "نظام عليم" 58 محاضرة ، سجل فيها (16,659) مستخدماً، أما عدد الثهادات المصدرة منذ تاريخ إفتناح النظام لحد الآن فهي (8,222) شهادة. 


\section{0/7 ملامح إحصائية أخرى لمنصة أريد}

إضـافة إلى ما سبق من سمات وخصائص "منصة أريد"، نود الإشارة إلى أن عدد السير الذاتية المرفوعة على المنصة بلغ 13,042 سيرة ذاتية. وبلغ عدد البحوث المقدمة الى المحفل العلمي الدولي بنسخهِ الست (1,023) بحثاً في مختلف المجالات العلمية. أما البحوث المقدمة إلى مجلات منصة أُريد الأربعة المحكمة فقد بلغ عددها (383) بحثثاً وعدد البحوث التي اجيزت للنشر \%) بحثاً أي أن نسبة القبول 25.5\%)

وبلغ عدد المشاريع البحثية المضافة للمنصة (2,255) مشرو عاً، في حين بلغ عدد الخبر ات التدريسية المضافة للمنصة (6,555) خبرة. واما ما يتعلق بعدد المتابعات (Follows) بين الأعضاء في منصة أُريد فقد بلغ (20,951) متابعة. في حين بلغ عدد المدونات الثخصية (2,100) مدونة، أما عدد روابط الصفحات الثخصية لمو اقع التو اصل الإجتماعي التي أضافها الباحثون الى صفحاتهم في المنصة ـ كرو ابط صفحات الفيسبوك و الباحث العلمي لجوجل وغير ها ـ فقد بلغ (2,100)

\section{8}

حاولنا في السطور السابقة التعرف على بعض الملامح البنيانية لمنصة أريد، ويمكن القول إن أعداد المستخدمين في "منصة أُريد" في تز ايد مستمر ، و هو ما يدل على أهمية دور ها الذي أنشئت من أجله، كما يدل على حاجة المجتمع العلمي العربي لمثل هذه المنصات البحثية الناطقة بالعربية. وكثفت النتائج أن العراق يتبوأ المرتبة الاولى في أعداد المسجلين في المنصة، وأن جامعة بغداد ـ من بين أبرز الجامعات العر اقية ـ تتبوأ الصدارة في أعداد المسجلين، ويعزى ذلك الى تشجيع وزارة التعليم العالي و البحث العلمي ورؤساء الجامعات الأكاديميين في العراق على التسجيل في المنصة وفاعلية اللجنة التنسيقية. وتتصدر المشاركة في المؤتمر ات قائمة الأنشطة الأكاديمية، حيث قارب عدد الباحثين فيها سبعة آلاف باحث، كما تجمع المنصة طيفًا و اسعاً من مختلف التخصصات، وإن كان يميل أكثر ها إلى العلوم الاجتماعية. وبالر غم من أن بعض التخصصات لا تتجاوز أعداد المسجلين فيها (300) باحث، مثل التمريض و علم المكتبات والصيدلة، إلا إن الكثير من التخصصات تجاوز أعداد المسجلين فيها (2,000) باحث مثل العلوم التربوية والعلوم و الآداب و العلوم السياسية. وقد تجاوز عدد المنشور ات العلمية الموجودة في منصة أُريد (12) ألف منشور، وهو عدد كبير ويعد نقطة جذب للباحثين والدارسين في المجالات المختلفة كمصادر 
لار اساتهم، وكان النصيب الأكبر للمقالات المنشورة في المجلات العلمية حيث تجاوز عددها تسعة آلاف مقالة؛ وهو شيء طبيعي في ظل أن المجلات أو الدوريات العلمية هي المحرك الرئيس للاتصسال العلمي في معظم تخصصات المعرفة البشرية. وتضم المنصة كماً كبيراً من حملة الشهادات العليا (الماجستير و الدكتوراه)، حيث تجاوز عددهم ثمانية آلاف، وهو شيء طبيعي في ظل أن المنصة في الأساس تعد منصة بحثية. و أما بالنسبة للمهارات العلمية فقد تصدرت مهارة البحث العلمي القائمة. و على صعيد التعليم الإلكتروني في المنصة، يعد نظام التعليم الألكتروني "عليم" إنجاز اً مهماً حيث استطاع أكثر من (16) ألف متدرب حضور المحاضر ات الموجودة في النظام خلال مدة ثلاثة أنشر من تاريخ بدء النظام، وبصفة خاصة في ظل ظاهرة الاستبعاد الاجتماعي الناتجة عن انتشار فيروس كورونا المستجد في أرجاء العالم. وبالر غم من جميع هذه الإنجاز ات الكبيرة للمنصة إلا أن أعداد المسجلين في بعض التخصصات يعد قليلاً، لذلك يوصى الباحثون بضرورة استهداف هذه التخصصات وتشجيعهم على الإنضمام الى المنصة ومشاركة نشاطاتهم العلمية. كما أن عدد المسجلين في بعض الدول العربية يعد قليلاً، لذلك يوصى الباحثون بضرورة نشر ثقافة الانضمام الى المنصة بين الباحثين في هذه الدول. كما يوصى الباحثون القائمون على المنصة بدمج الأنشطة العلمية مع المنشور ات لتكون المنشورات جزءاً من الأنشطة العلمية للحصول على نتائج أكثر دقة. كما نوصيهم بابتكار مؤشر خاصة بمدى تأثبر الباحثين في المنصة، على غرار المؤشرات المختلفة لمنصة (ResearchGate (RG) و غير ها من المنصات العالمية. إضافة إلى ذللى، فإن ثقافة العمل الجماعي والمجمو عات البحثية بحاجة الى تفعيل بين الناطقين بالعربية وذلك عبر عقد دورات ومحاضرات عن هذا الموضوع في نظام عليم. وأخيرًا، فإنه من الضرورة بمكان تثجيع الباحثين على در اسة خصائص المنصات الرقمية المختلفة التي تقدم خدماتها للناطقين و المتحدثين بالعربية، حيث وجدنا شحًا شديدًا في هذه الدر اسات أثناء إعدادنا لهذه الدر اسة. 
Ali, M. Y., \& Richardson, J. (2019). Google Scholar Citation metrics of Pakistani LIS scholars: an overview. Global Knowledge, Memory and Communication .

Asadullah, A., Faik, I., \& Kankanhalli, A. (2018). Digital Platforms: A Review and Future Directions .Paper presented at the PACIS.

Copiello, S. (2019). Research Interest: another undisclosed (and redundant) algorithm by ResearchGate. Scientometrics, 120(1), 351-360 .

Copiello, S., \& Bonifaci, P. (2019). ResearchGate Score, full-text research items, and full-text reads: a follow-up study. Scientometrics, 119(2), 1255-1262 .

Ebrahimy, S., Mehrad, J., Setareh, F., \& Hosseinchari, M. (2016). Path analysis of the relationship between visibility and citation: the mediating roles of save, discussion, and recommendation metrics. Scientometrics, 109(3), 1497-1510 .

Kademani, B., Kalyane, V., \& Kumar, V. (2001). Scientometric portrait of nobel laureate Ahmed Hassan Zewail. Malaysian Journal of Library \& Information Science, 6(2), 53-70 .

Kirby, S. R. (1991). Reviewing United States history monographs: a bibliometric survey. Collection building .

Martín-Martín, A., Orduña-Malea, E., \& López-Cózar, E. D. (2018). Author-level metrics in the new academic profile platforms: The online behaviour of the Bibliometrics community. Journal of informetrics, 12(2), 494-509 .

Mowafi, H. A. (2012). Bibliometric analysis of the volume and visibility of Saudi publications in leading anesthesia journals. Saudi journal of anaesthesia, 6(4), 393 .

Rehn, C., Kronman, U., Gornitzki, C ,.Larsson, A., \& Wadskog, D. (2008). Bibliometric handbook for Karolinska Institutet. Huddinge: Karolinska Institutet .

$$
\begin{aligned}
& \text { المجمو عات البحثية. (2020). Retrieved 4/6/2020, from جامعة الملك سعود، عمادة البحث العلمي } \\
& \text { https://dsrs.ksu.edu.sa/ar/researchgroups } \\
& \text { تاجيو, س. ج. (2000). قياسات المعلومات/ ترجمة عبدالرحمن فر اج. مج2، ع1 (يوليو 2000). عالم المعلومات و المكتبات } \\
& \text { و النشر., ص ص 140-144. } \\
& \text { سلمان, ع. م. (2019, } 26 \text { - } 25 \text { يوليو ). التحديات الجيوفيزيائية و الاجتماعية و الانسانية و الطبيعية في بيئة متغيرة. Paper } \\
& \text { presented at the } \\
& \text { سيف السويدي, ط. ب. (2018). صناعة الهوية العلمية العالمية للخبر اءو والباحثين. ماليزيا. }
\end{aligned}
$$


عبد المجيد صالح بوعزة, ي. أ. ا. (2009). اتجاهات أعضاء هيئة التدريس بجامعة الإمارات نحو نظام الوصول الحر إلى المعلومات العلمية. المجلة العربية للأرشيف و التوثيق و المعلومات, 25 / 26, 9 - 43.

فر اج, ع. (2015). تاريخ المملكة العربية السعودية في الرسائل العلمية المجازة من الجامعات العربية و الغربية: ور اقية، ودر اسة تحليلية. الرياض: جامعة الإمام محمد بن سعود الإسلامية، كرسي الثيخ عبدالعزيز التويجري للار اسات الإنسانية, 335ص.

فر اج, ع. (2016). قياسات المعلومات في مطلع القرن الحادي والعشرين. Paper presented at the لمؤتمر الدولي لقياسات المعلومات ومعامل التأثير العربي". الأسكندرية: الأكاديمية العربية للعلوم والتكنولوجيا و النقل البحري، ودار العلوم الطبيعية للنشر الدولي. متاح على الر ابط: https://zenodo.org/record/3445462\#.XfSvcpMzbIU. تم الوصول إليه في 2020/15.

فر اج, ع. (2017). الوصول الحر للمعلومات: طريق المستقبل في الأرشفة والنشر العلمي. مجلة مكتبة الملك فهد الوطنية. مج16، ع1 (ديسمبر 2009-يونيو 2010), ص ص ص 213-234.

قاسح, ح. (1980). تحليل الاستشهادات المرجعية وتطور القياسات الور اقية. المجلة العربية للمعلومات. مج3، ع4 (ديسمبر 1980), ص ص ص11-11.

قاسح, ح. (2020). الدوريات المتخصصة؛ نطور ها وقضاياها المعاصرة. تحرير عبدالرحمن فر اج. القاهرة: دار الفجر للنشر و التوزيع, 142ص.

/from https://arid.my ماهي منصة اريد. (2016). 2020 2020 مايو 9 20trieved, محمد, ع. ا. م. ش. (2019). بناء منصة تعليمية تفاعلية مبتكرة على شبكة الإنترنت. Paper presented at the المؤتمر

$$
\text { الدولي السابع للتطبيقات الإسلامية في علوم الحاسوب و تقنتياته. }
$$

نذير, غ. (2010). الخدمات الإلكترونية بالمكتبات الجامعية :دراسة ميدانية بمؤسسات التعليم العالي بجامعات قسنطينة. (رسالة

$$
\text { دكتور اه), جامعة منتوري قسنطينة, قسنطينة ــ الجزائر. }
$$

